José Ignacio Saavedra Cruz ${ }^{*}$

\title{
Auditorías Ambientales Independientes: a la luz del Proyecto de Ley que rediseńa la institucionalidad ambiental ${ }^{1}$
}

\section{Introducción}

La intervención administrativa en el desarrollo de actividades económicas ${ }^{2}$, a fin de proteger los bienes individuales y colectivos ante los riesgos del desarrollo económico, ha significado la aplicación de variadas reglamentaciones con un elevado contenido técnico, para lo cual se ha instaurado un sistema administrativo de controles, de inspecciones y certificaciones de productos, procesos e instalaciones industriales, que conlleva también numerosas y complejas exigencias técnicas. ${ }^{3}$

Esta complejidad ha afectado la capacidad de las estructuras materiales y personales de la Administración dado que el cúmulo y la dificultad de los controles previstos legal y reglamentariamente escapan de sus efectivos, por lo que el remedio prescrito para atender la incapacidad de la organización administrativa ante el elemento de la técnica, es recurrir a la colaboración de instancias privadas con la capacidad y el co-

* Abogado,

Universidad de

Chile. Ayudante

de Derecho del

Medio Ambiente y candidato a Magister

en Derecho, mención

en Derecho Público,

ambos en la Facultad

de Derecho de la

Universidad de

Chile.
El presente trabajo versa en gran medida sobre las modificaciones a la institucionalidad ambiental que contempla el Proyecto de Ley que Crea el Ministerio, el Servicio de Evaluación Ambiental y la Superintendencia del Medio Ambiente, $\mathrm{N}^{\circ}$ Boletín: 5947-12, el cual ingresó al Congreso Nacional con fecha 3 de julio de 2008, siendo aprobado por la Cámara de Diputados y, a la fecha de la entrega del presente trabajo, en discusión en el Senado. Debido a que el referido proyecto de ley está actualmente en tramitación y probablemente sea modificado, se ha preferido no hacer referencias al articulado. Sin perjuicio de esto, cabe hacer presente que la discusión parlamentaria no ha girado en torno a modificar el Proyecto de Ley en materia de auditorías y certificaciones ambientales, por lo que no se prevén cambios sustanciales en esta materia. Para seguir la tramitación legislativa consúltese: http://sil. congreso.cl/pags/index.html

El fenómeno de la colaboración privada en el ejercicio de funciones de control en materia ambiental se encuentra estrechamente ligada al control en materia de seguridad, puesto que éste tiene legalmente por objeto la prevención y limitación de riesgos, así como la protección contra accidentes y siniestros capaces de producir daños al medio ambiente derivados de la actividad industrial. FERNÁNDEZ, S. "La Colaboración Privada en la Actividad de Inspección”, La Actividad Administrativa de Inspección, Editorial Comares, España, 2002, página 507.

CANALS, D. "El Ejercicio por Particulares de Funciones de Autoridad (Control, Inspección y Certificación)", Editorial Comares, España, 2003, página 49. 
nocimiento requerido para ejercer las funciones de inspección, control y certificación reglamentarias. ${ }^{4}$

En este ámbito, las Auditorías Ambientales Independientes (AAI) han surgido en muchos países como una herramienta de apoyo para la labor de fiscalización ambiental de proyectos y actividades económicas, debido principalmente a que la Administración no siempre cuenta con los medios suficientes ni con la capacidad técnica adecuada.

No obstante, el desarrollo de las AAI en Chile se ha desenvuelto sin tener una regulación legal expresa, ya que, ha sido la práctica administrativa la que ha establecido en ciertos casos la necesidad de contar con un "apoyo extra", imponiéndolas como una condición o exigencia ambiental de ciertas Resoluciones de Calificación Ambiental (RCA) .

En este sentido, el Proyecto de Ley de Rediseño de la Institucionalidad Ambiental (actualmente en discusión en el Congreso Nacional) viene a llenar el vacío normativo en el cual se encuentran las AAI, estableciendo cambios sustanciales en la materia, entre ellos, su naturaleza jurídica, las garantías mínimas para su desarrollo y la generación de incentivos para el cumplimiento de la normativa ambiental.

El presente trabajo tiene por objeto analizar bajo el prisma del Derecho Administrativo, la situación actual de las AAI, en contraste con el mecanismo que propone el Proyecto de Ley en materia de colaboración privada en el ejercicio de las funciones de fiscalización ambiental, a fin de comprender las implicancias y efectos de dicho cambio legislativo en la figura de las AAI.

\section{El SEIA y la potestad de fiscalización ambiental}

El Sistema de Evaluación de Impacto Ambiental (SEIA) es un instrumento de gestión ambiental contemplado en la Ley 19.300. Según CORDERO, "entendemos como instrumentos de gestión ambiental, el conjunto de actos administrativos que, individual o combinadamente, sirven para realizar y ejercer las potestades de la Administración con la precisa finalidad de resguardar y proteger el medio ambiente, preservar la naturaleza y conservar el patrimonio ambiental" 6 .

Una de las principales características del SEIA radica en que se identifica con el principio preventivo del Derecho Ambiental, por cuanto está llamado a reconocer y calcular con anterioridad a la ejecución de un proyecto o actividad cuales serán los impactos que se

CANALS, op. cit., páginas 50 y 51 .

A modo de ejemplo, se pueden mencionar las siguientes RCAs que establecen AAI como condición de cumplimiento: Resolución Exenta No 0212/2008, COREMA Región de Antofagasta; Resolución Exenta No 2003/2004, COREMA Región de Valparaíso; Resolución Exenta No 594/2005 (establece Auditoría Ambiental Nacional y Auditoría Ambiental Internacional), COREMA Región de Los Lagos; y Resolución Exenta No 038/2004, COREMA Región de Coquimbo.

6 CORDERO, L. "Justificación de la Intervención Administrativa en el Medio Ambiente" en Primeras Jornadas Nacionales de Derecho Ambiental, CONAMA y CDA, LOM Ediciones, Santiago, 2003, página 235. 
prevé causar en el medio ambiente, con el objeto de adoptar las medidas necesarias para que no se produzcan o se minimicen.

Desde el enfoque del Derecho Administrativo, es preciso señalar que se trata de un procedimiento de carácter administrativo que concluye con un acto administrativo denominado resolución de calificación ambiental $(\mathrm{RCA})^{8}$, mediante la cual se puede calificar favorablemente o desfavorablemente un proyecto a actividad sometido a evaluación ambiental. Con la dictación de la RCA finaliza la etapa de evaluación ambiental, lo que implica que el titular se encuentra en condiciones de ejecutar su proyecto o actividad.

El término de la etapa de evaluación ambiental ${ }^{9}$ no implica que la actividad de la autoridad administrativa culmine, sino que, la intervención del Estado se manifestará en la etapa de seguimiento, esto es, durante las fases de ejecución de un proyecto o actividad: construcción, operación y cierre.

Siguiendo la clasificación de autorizaciones administrativas planteadas por CAMA$\mathrm{CHO}$, se concluye que la RCA es una autorización administrativa de funcionamiento o efecto continuado, por cuanto recae sobre un proyecto o actividad que se realiza de modo continuo y con vocación de permanencia en el tiempo, de manera que la autorización integra el régimen al que está sometida dicha actividad y tiene la potencialidad de mantenerse vigente en tanto dicha actividad se desarrolle. ${ }^{10}$

Respecto de este tipo de autorizaciones, "la Administración tiene facultades de fiscalizar el cumplimiento de las exigencias no sólo al inicio de la actividad, sino que se ejerce un control sucesivo sobre el ejercicio de la actividad que busca asegurar el cumplimiento sostenido en el tiempo de las exigencias que permitieron el otorgamiento"11.

En consecuencia, una vez que se ha evaluado y calificado favorablemente un determinado proyecto o actividad sometido al SEIA, la intervención de la Administración del Estado en aras de proteger el medio ambiente, se debe materializar mediante la potestad de inspección o fiscalización.

BERMEJO sostiene que, en términos generales, se habla de función o potestad de inspección para identificar actuaciones previstas en el ordenamiento jurídico, que ha-

LAVÍN, J. "El SEIA: Visión Critica a 10 años de su Vigencia”, en Foco No 95, Expansiva, Santiago, 2006, página 2.

8 El artículo 2, letra j), de la Ley 19.300 define "Evaluación de Impacto Ambiental”, en los siguientes términos: “ $E l$ procedimiento, a cargo de la Comisión Nacional del Medio Ambiente o de la Comisión Regional respectiva, en su caso, que, en base a un Estudio o Declaración de Impacto Ambiental, determina si el impacto ambiental de una actividad o proyecto se ajusta a las normas vigentes". Además, el carácter de procedimiento administrativo se encuentra explicitado en los artículos 13 y 14 de la Ley 19.300 .

9 El SEIA como un instrumento de gestión ambiental compuesto de dos etapas fue planteado en DE LA FUENTE, O. y MORA, R. "Grupos de Interés y Participación Ciudadana en el SEIA: Un Enfoque Económico", en Desarrollo Sustentable: Gobernanza y Derecho, Actas de las Cuartas Jornadas de Derecho Ambiental, Centro de Derecho Ambiental, Universidad de Chile, 2008, páginas 570 y siguientes.

10 CAMACHO, G. "La Actividad Sustancial de la Administración del Estado", en Pantoja, R. (coordinador), Derecho Administrativo Chileno, UNAM, Porrúa, México, 2007, página 426.

11 CAMACHO, op. cit., página 426. 
bilitan a las Administraciones Públicas para llevar a cabo funciones de comprobación o constatación de cumplimiento de la normativa vigente, en su sentido más amplio, esto es, incluidas las condiciones y requisitos de orden técnico, consecuencia inherente de la imposición que a determinadas personas, actividades, instalaciones, objetos y productos hacen ciertas normas jurídicas. ${ }^{12}$

$\mathrm{Al}$ respecto, el inciso primero del artículo 64 de la Ley 19.300 sobre Bases Generales del Medio Ambiente dispone que:

"Corresponderá a los organismos del Estado que, en uso de sus facultades legales, participan en el sistema de evaluación de impacto ambiental, fiscalizar el permanente cumplimiento de las normas y condiciones sobre la base de las cuales se aprobó el Estudio o se aceptó la Declaración de Impacto Ambiental. En caso de incumplimiento, dichas autoridades podrán solicitar a la Comisión Regional o Nacional del Medio Ambiente, en su caso, la amonestación, la imposición de multas de hasta quinientas unidades tributarias mensuales e, incluso, la revocación de la aprobación o aceptación respectiva, sin perjuicio de su derecho a ejercer las acciones civiles o penales que sean procedentes".

Por consiguiente, son precisamente los órganos de la Administración del Estado con competencia ambiental ${ }^{13}$ quienes están facultados para ejercer la potestad de fiscalización en materia ambiental y no la Comisión Regional o Nacional del Medio Ambiente (COREMA o CONAMA, respectivamente), siendo que estos últimos, según sea el caso, sólo les corresponde la administración y la coordinación de los organismos públicos con competencia ambiental en el marco del SEIA para efectos de obtener los permisos o pronunciamientos de carácter ambiental, conforme lo establece el artículo 8 de la Ley $19.300^{14}$.

Concordante con lo anterior, los dictámenes de la Contraloría General de la República No 981/2003 y No 39.696/2005 establecen que "los organismos sectoriales de la Administración del Estado no pueden ejercer su potestad sancionatoria, en relación con los aspectos ambientales de los proyectos o actividades que cuentan con un EIA aprobados, toda vez que dicha potestad se encuentra radicada en la COREMA o CONAMA, que calificó ambientalmente favorable el respectivo proyecto o actividad".

12 BERMEJO, J. "La Actividad Inspectora", en Revista de Administración Pública”, No 147, Espańa, septiembre diciembre 1998, páginas 40 y 41 .

13 Conforme lo establecido en el artículo 2 letra e) del Reglamento del SEIA, refundido, coordinado y sistematizado por el artículo 2 del Decreto Supremo 95/2002 del Ministerio Secretaría General de la Presidencia, se entiende por "órgano de la Administración del Estado con competencia ambiental" aquel: "Ministerio, servicio público, órgano o institución creado para el cumplimiento de una función pública, que otorgue algún permiso ambiental sectorial de los señalados en este Reglamento, o que posea atribuciones legales asociadas directamente con la protección del medio ambiente, la preservación de la naturaleza, el uso y manejo de algún recurso natural y/o la fiscalización del cumplimiento de las normas y condiciones en base a las cuales se dicta la resolución calificatoria de un proyecto o actividad".

14 Asimismo, conforme lo establece el artículo 23 de la Ley 19.300, la Comisión Nacional del Medio Ambiente “(...) procurará uniformar los criterios, requisitos, condiciones, antecedentes, certificados, trámites, exigencias técnicas y procedimientos de carácter ambiental que establezcan los Ministerios y demás organismos del Estado competentes". 
Por lo tanto, el artículo 64 de la Ley 19.300 restringe la actuación de los órganos con competencia ambiental a la solicitud de sanción. ${ }^{15}$

De esta manera, el sistema de institucionalidad ambiental descansa sobre la base de la coordinación, sin producir efectos explícitos de derogación de las competencias sectoriales. La completa sectorialización del modelo de fiscalización ambiental chileno, explica porque los componentes ambientales tiene diversos fiscalizadores, con procedimientos diferentes y con un sistema sancionatorio propio en cada caso. ${ }^{16}$ Como se verá más adelante, este modelo de fiscalización ambiental no está exento de críticas.

En cuanto al objeto de la fiscalización ambiental, el inciso primero del artículo 64 de la Ley 19.300 se refiere a la facultad legal de los organismos del Estado de "fiscalizar el permanente cumplimiento de las normas y condiciones sobre la base de las cuales se aprobó el Estudio o se aceptó la Declaración de Impacto Ambiental'. Es preciso distinguir que sólo se debe cumplir con la normativa ambiental aplicable, sino que, además con las condiciones o exigencias ambientales específicas exigidas por la autoridad en el marco del SEIA, incluyendo los compromisos voluntarios.

En caso de tratarse de un EIA, la autoridad debe verificar que las medidas (de mitigación, compensación y reparación) del Plan de Manejo Ambiental se desarrollen de la manera prevista y cumplan sus objetivos. Junto con lo anterior, corresponderá también verificar el desarrollo del Plan de Seguimiento Ambiental, el cual tiene por finalidad asegurar que las variables ambientales relevantes evolucionen según los pronósticos realizados en la evaluación ambiental ${ }^{17}$.

En caso de verificación o constatación de incumplimiento de la normativa y/o condiciones ambientales, la potestad de inspección puede concluir en el ejercicio de la potestad sancionatoria, e incluso en el surgimiento de responsabilidades derivadas del incumplimiento. ${ }^{18}$ En este sentido, es importante no perder de vista que el principal objetivo de un sistema de fiscalización es que exista cumplimiento de las regulaciones ambientales de manera de evitar efectos adversos sobre el medio ambiente, por lo que su finalidad debiese ser esencialmente preventiva, para luego ser reactiva. ${ }^{19}$

En conclusión, se requiere y justifica la intervención administrativa durante todas las etapas (evaluación y seguimiento) del SEIA, puesto que, es precisamente en esta última cuando se manifiestan los impactos ambientales (y eventualmente en caso de ser significativos, daño ambiental). En definitiva, la Administración del Estado debe

15 PRECHT, A. "Procedimiento Sancionatorio del Artículo 64 de la LBGMA: Aspectos Legales y Jurisprudenciales", en Desarrollo Sustentable: Gobernanza y Derecho, Actas de las Cuartas Jornadas de Derecho Ambiental, Centro de Derecho Ambiental, Universidad de Chile, 2008, páginas 69 y 70.

16 CORDERO, L. "Evaluando el Sistema de Fiscalización Ambiental Chileno", en Desarrollo Sustentable: Gobernanza y Derecho, Actas de las Cuartas Jornadas de Derecho Ambiental, Centro de Derecho Ambiental, Universidad de Chile, 2008, páginas 33 y 34.

Artículo 63 del Reglamento del SEIA.

18 BERMEJO, op. cit., página 55.

19 CORDERO, L. (2008), op. cit., página 41. 
llevar todas sus potestades al ejercicio completo de ellas, esto es, durante el ejercicio entero de la actividad, incluyendo todas sus fases, con el objeto de beneficiar o evitar perjuicios en el medio ambiente" 20 .

\section{Las auditorías ambientales independientes}

\subsection{Contexto}

En el actual modelo de institucionalidad ambiental, la gestión ambiental resulta en extremo difícil de lograr si se considera que "uno de los rasgos más característicos del SEIA chileno es el perfil coordinador de CONAMA, aspecto que se deriva de la concepción de que el medio ambiente es un tema eminentemente transectorial. En consecuencia, el concepto de autoridad ambiental no se satisface sólo por la instancia administradora del Sistema, sino también por el conjunto de organismos del Estado con competencia ambiental..." 21 .

En este sentido, ASTORGA sostiene que "la actual superposición de competencias, la ineficiencia en la utilización de recursos humanos y materiales y el modelo coordinador no han brindado resultados suficientes para garantizar efectivamente el cumplimiento de la legislación ambiental" 22 .

Si bien no existe un diagnóstico acabado y claro sobre el nivel de cumplimiento de la normativa ambiental en Chile, existen críticas asociadas a la dispersión y superposición de competencias fiscalizadoras, al monto y ejecución de sanciones por incumplimiento de la norma, al deterioro del medio ambiente, a la falta de certeza sobre los criterios de la autoridad, entre otros aspectos. ${ }^{23}$

A su vez, debe agregarse que "resulta evidente que el SEIA no ha recibido la fiscalización acorde a la numerosa y variada gama de exigencias que se imponen a los proyectos de inversión, en las resoluciones de calificación ambiental. Ello se debe a la falta de personal y de recursos de la administración pública, insuficiencia que impide la finalidad del SEIA de hacer una gestión eficiente del medio ambiente..."24.

En efecto, la experiencia ha demostrado que existen una serie de factores (falta de personal, falta de recursos, falta de capacidad técnica, falta de coordinación, dispersión y superposición de competencias, entre otros) que dificultan la función pública de fiscalización de los proyectos o actividades sometidos al SEIA.

CORDERO (2003), op. cit, página 235.

ASTORGA, E. “Derecho Ambiental Chileno, Parte General”, Lexis Nexis, Santiago, 2007, página 95.

22 ASTORGA E. "Aportes a la nueva institucionalidad ambiental chilena: Propuesta sobre creación del Ministerio del Medio Ambiente de la Presidenta Michelle Bachelet", en Actas de las Terceras Jornadas de Derecho Ambiental, Centro de Derecho Ambiental, Facultad de Derecho, Universidad de Chile, Santiago, 2006, página 354.

23 CORDERO (2008), op. cit., página 33.

24 LAVÍN, op. cit., página 12. 
En este ámbito, es fundamental tener presente que la protección ambiental depende de la eficacia de los instrumentos de gestión ambiental, ya que, ésta será una mera declaración si no se cuenta con una adecuada fiscalización de los mismos. ${ }^{25}$

En este contexto, las AAI actualmente responden a la necesidad de la Administración de contar con un "apoyo extra" que permita que ciertos proyectos y actividades sometidos al SEIA, especialmente aquellos de mayor complejidad y envergadura, sean debidamente fiscalizados. Aunque las AAI han solucionado algunas falencias del sistema de fiscalización, la forma en que se han llevado a cabo resulta bastante cuestionable, puesto que, se encuentran en un estado de vacío legal, lo cual conlleva un sinnúmero de situaciones ambiguas e irregulares que es preciso corregir.

\subsection{Análisis Jurídico de las AAI}

Las AAI encuentran actualmente su origen en las condiciones o exigencias ambientales que puede imponer la autoridad ambiental a determinados proyectos o actividades sometidos al SEIA. Por cierto, la exigencia o condición de implementar una AAI constituye una facultad discrecional de la autoridad ambiental y sólo procederá en los casos que ésta lo estime pertinente.

Dicha facultad de imponer condiciones o exigencias ambientales se encuentra contenida en el artículo 25 de la Ley 19.300, el que dispone que:

"El certificado a que se refiere el artículo anterior -la RCA-, establecerá, cuando corresponda, las condiciones o exigencias ambientales que deberán cumplirse para ejecutar el proyecto o actividad y aquéllas bajo las cuales se otorgarán los permisos que de acuerdo con la legislación deben emitir los organismos del Estado".

En consecuencia, las AAI al encontrar su sustento en la RCA, surgen como una manifestación del ejercicio de las facultades que tiene la autoridad ambiental para establecer discrecionalmente condiciones o exigencias ambientales para la ejecución de un determinado proyecto o actividad $^{26}$.

En cuanto a la labor misma que realizan las AAI, se suele contemplar en las RCAs que su finalidad es "apoyar a los servicios competentes en la labor de fiscalización" o "garantizar un adecuado seguimiento a todas las fases del proyecto", entre otras expresiones similares.

25 BERMÚDEZ, J. "Bases jurídicas para la acuicultura sustentable y aplicación de la certificación ambiental como instrumentos de gestión ambiental", en Actas de las Terceras Jornadas de Derecho Ambiental, Centro de Derecho Ambiental, Facultad de Derecho, Universidad de Chile, Santiago, 2006, página 287.

26 Sin perjuicio de esto, el origen de una AAI podría incluso emanar de la voluntad del propio titular del proyecto o actividad, el que asume ser auditado como un compromiso ambiental voluntario. En este sentido, es preciso aclarar que, aún cuando el compromiso de ser auditado ambientalmente sea voluntario, si se incluye como condición o exigencia ambiental de la RCA, éste pasa a ser parte integrante de ella, por ende, su cumplimiento se transforma en obligatorio. En razón de lo anterior, no es posible asimilar a las AAI a un fenómeno de autorregulación, como en el caso de las ecoauditorías, auditorías ISO 14.000, etc. 
Se advierte que en el caso chileno existe una especie de contradicción entre la regulación de las AAI y su finalidad. En primer término, su finalidad es apoyar a la administración en la labor de fiscalizar a ciertos proyectos o actividades sometidos al SEIA, lo cual se traduce en realizar las mismas labores que los órganos de la Administración con competencia ambiental ejercen en su rol de fiscalizadores. En efecto, se encomienda a los auditores verificar el cumplimiento de los compromisos ambientales y/o las condiciones establecidas en la RCA, en especial ${ }^{27}$ :

- La normativa ambiental aplicable al proyecto;

- Los planes de mitigación, reparación y/o compensación, de prevención de riesgos y los planes de control de accidentes definidos en el Estudio de Impacto Ambiental y sus Adenda;

- El plan de seguimiento ambiental establecido en el Estudio de Impacto Ambiental y sus Adenda;

- Las condiciones establecidas en la RCA del proyecto para hacerse cargo de los efectos, características y circunstancias del artículo 11 de la Ley No 19.300;

- La aplicación de las medidas para evitar o disminuir los daños a la salud de la población y al medio ambiente, en caso de accidentes o emergencias, en función de las medidas de prevención de riesgos y control de accidentes.

- Detectar los impactos negativos no previstos durante el proceso de evaluación ambiental del proyecto;

- Detectar los impactos negativos cuya magnitud sea distinta a la prevista durante el proceso de evaluación ambiental del proyecto;

- Verificar que el Plan de Seguimiento Ambiental definido en el Estudio de Impacto Ambiental y sus Adenda sea el adecuado para el seguimiento de ciertas variables.

En esta materia, se sostiene que la característica de la función inspectora o fiscalizadora es el habilitar la realización de funciones específicas de comprobación o constatación de legalidad, siendo un requisito esencial, inherente a toda potestad, su necesaria atribución legal a la administración competente en cumplimiento del principio de legalidad. ${ }^{28}$

Sin embargo, la Administración Pública no está habilitada para delegar la función pública en los particulares y, quienes desarrollan las AAI no están directamente facultados por el Ordenamiento Jurídico para realizar dichas funciones públicas. Por ende, se recurre a mecanismos poco ortodoxos para amparar su existencia.

Si bien la obligación de implementarlas emana de un acto administrativo, se rigen

27 Objetivos de AAI extraídos de la Resolución Exenta No 038/2004, COREMA Región de Coquimbo. En general, las RCAs que incluyen la condición o exigencia de implementar una AAI establecen los mismos objetivos.

28 CAMACHO, op. cit., página 431. 
por un contrato entre privados (el titular del proyecto o actividad y el auditor). Por lo mismo, la "regulación" de la labor de las AAI se realiza por la autoridad caso a caso, mediante documentos conocidos como "Protocolos de AAI", en los cuales se establecen los objetivos, alcances y metodología de aplicación de la auditoría ${ }^{29}$. Dichos protocolos son previamente visados por una resolución administrativa de la autoridad ambiental.

En mi opinión, por esta vía se pretende otorgar a las AAI una apariencia de legalidad, en el sentido de estar legalmente facultadas para desarrollar funciones de fiscalización y de estar sujetas al control administrativo.

Sin embargo en estricto rigor, los servicios que desarrolla el auditor se rigen por el Derecho Privado, toda vez que la prestación de servicios emana de un contrato, entre el titular y el auditor, sin participación de la autoridad ambiental.

Por ende, como no existe una norma legal que faculte a la autoridad a delegar dicha potestad pública, se recurre a esta especie de híbrido para suplir una falencia del sistema, pero con numerosas consecuencias que desvirtúan y le quitan valor a la labor de los auditores ambientales, en comparación con el rol de las AAI en la experiencia comparada ${ }^{30}$.

Por cierto, las AAI no pueden emitir certificaciones de cumplimiento, las cuales constituyen la principal ventaja de implementar un sistema de auditorías ambientales. A su vez, los informes emitidos en el marco de las AAI no tienen carácter de vinculantes, es decir, sus informes no son más que antecedentes para que la autoridad evalúe el cumplimiento de la RCA, pero carentes de todo valor jurídico.

Por otra parte, se puede constatar que se generan ineficiencias, toda vez que al no existir una delegación legal (total o parcial) de la función pública de fiscalización a los auditores ambientales, los órganos con competencia ambiental deben seguir realizando sus funciones habituales de fiscalización, mediante la revisión de documentación relevante y las visitas en terreno del respectivo Comité Operativo de Fiscalización $(\mathrm{COF})^{31}$. En la práctica, estas visitas del COF suelen ser acompañadas por la visita de los auditores ambientales, lo que genera dudas en torno a la eficiencia de dicha fiscalización ambiental, debido a la duplicidad de funciones. ${ }^{32}$

La elección del auditor se realiza previamente por la autoridad ambiental, generalmente después de que el titular ha presentado una terna para tal efecto.

30 En el derecho comparado, la actividad de las entidades colaboradoras no se circunscribe a una actividad puramente material o de soporte de la actividad jurídica de la Administración, pues se concreta precisamente en una actividad jurídica, declarativa, que ésta la autoridad asume como propia, con efectos públicos ante ellas y terceros. Es más, en muchos casos se conceptualiza de "administrativa" la actuación de los sujetos privados, partiendo de la base de que lo relevante es la función o actividad ejercida y no tanto el carácter público o privado de la entidad que lo emite. En el caso de Espańa, doctrinaria y jurisprudencialmente se ha aceptado esta tesis. CONAMA, op. cit., página 49 y nota al pie de página 107.

31 El COF se compone por representantes de los distintos órganos de la Administración del Estado con competencia en materia ambiental.

32 Por otra parte, se han alzado críticas a la constitución de los COFs debido a que "ellos ejercerían un esfuerzo incompleto, puesto que, en la práctica ha significado que la CONAMA actúe muchas veces como órgano líder 
En el derecho comparado la situación es diametralmente distinta, ya que, la actuación de los privados en labores de inspección y control de la normativa ambiental, se contempla como un mecanismo de colaboración privada en una función pública de fiscalización ambiental ${ }^{33}$.

Esto se fundamenta en el hecho de que quienes desarrollan las auditorías son organismos técnicos de carácter privado y, al mismo tiempo, la función que desarrollan constituye una función pública conferida legalmente a los órganos de la administración del Estado con competencia ambiental ${ }^{34}$.

El hecho de que la potestad pública de fiscalización sea conferida por ley a la Administración resulta particularmente relevante, pues constituye la piedra de tope en nuestra legislación para considerar la posibilidad de delegar funciones públicas en manos de privados, debido a que no se cuenta con el debido respaldo legal.

Al respecto, GARCÍA DE ENTERRÍA señala que la potestad de inspección "no se genera en relación jurídica alguna, ni en pactos, negocios jurídicos o actos o hechos singulares, sino que procede directamente del Ordenamiento" 35 . En este mismo sentido, CAMACHO sostiene que "la actividad de inspección es una función pública titularizada en la administración con independencia de que -en algunos casos en que la ley faculte o prescriba- esta actividad pueda ser llevada materialmente con colaboración de agentes privados" 36 .

Por consiguiente, resulta evidente que la colaboración de los particulares en las funciones públicas de fiscalización sólo puede proceder en los casos previstos en la ley. Incluso, se puede sostener que pretender que las AAI sean un caso de colaboración privada en funciones públicas, sin contar con un sustento legal, implicaría que dicha actividad es contraria al principio de juridicidad, al conferirse la Administración más atribuciones de las que expresamente le haya conferido el Ordenamiento Jurídico ${ }^{37}$.

En igual sentido, se sostiene en un documento elaborado por CONAMA que la razón de esta exigencia legal reside en que el fenómeno de colaboración privada en funciones públicas "implica una intersección de los público y lo privado que no puede ser

de un grupo fiscalizador (competencia de la que carece) y los servicios públicos no ejerzan sus facultades de fiscalización en forma preponderante". Crítica expresada en GUZMÁN F. "Sistema de Fiscalización Ambiental. Situación Actual y Propuestas para Mejorar su Eficiencia”, en Desarrollo Sustentable: Gobernanza y Derecho, Actas de las Cuartas Jornadas de Derecho Ambiental, Centro de Derecho Ambiental, Universidad de Chile, 2008, página 60.

33 Un completo estudio del caso espańol, se encuentra en DOLORS y FERNÁNDEZ, en las respectivas obras ya citadas. Para tener una referencia del modelo alemán, véase BERMÚDEZ (2006), op. cit.

34 En nuestra legislación, la fiscalización ambiental constituye una función pública, conforme lo dispone elartículo 64 de la Ley 19.300 y el artículo 2, letra e), del Reglamento del SEIA.

35 Citado en BERMEJO, op. cit., página 42.

36 CAMACHO, op. cit., página 433.

37 En este sentido, se contravendría el artículo 2 de la Ley 18.575, Orgánica Constitucional de Bases Generales de la Administración del Estado, el que en armonía con el artículo 6 de la Constitución Política, establece que: "Los órganos de la Administración del Estado someterán su acción a la Constitución y a las leyes. Deberán actuar dentro de su competencia y no tendrán más atribuciones que las que expresamente les haya conferido el ordenamiento jurídico". 
libremente acordada por la Administración Pública. Implica la cesión de cometidos propios y exclusivos de la Administración -lo público- a favor de particulares" ${ }^{\prime 3}$.

Según FERNANDEZ, la función inspectora constituye una "inequívoca potestad administrativa”, por ello parece razonable entender que sólo por ley se puede facultar a un particular el ejercicio de funciones públicas, inicialmente encomendadas por el ordenamiento jurídico a la Administración, razón por la cual debe propugnarse la necesidad de que esta intervención de sujetos privados en una función pública cuente con la adecuada cobertura legal. ${ }^{39}$

En razón de lo expuesto, las actuales AAI de ninguna manera pueden considerarse como un caso de colaboración privada en funciones públicas, puesto que:

- No existe una norma legal que autorice la delegación de la función pública de fiscalización a los privados.

- No hay delegación de la potestad públicas de fiscalización ambiental (sigue completamente en manos de los órganos con competencia en materia ambiental).

- Las AAI no pueden emitir certificaciones ambientales con valor jurídico.

- El rol de los auditores ambientales es meramente informativo y no emiten decisiones vinculantes.

- Su régimen jurídico es de Derecho Privado.

- $\quad$ Su origen puede ser voluntario.

Se concluye entonces que la labor de los auditores ambientales responde al cumplimiento, por parte del titular de un proyecto o actividad sometido al SEIA, de una condición o exigencia ambiental de la respectiva RCA. Por lo tanto, su naturaleza jurídica, ciertamente ambigua, no corresponde a un caso de colaboración privada en funciones públicas, sino que, más bien es parte de la gestión ambiental que el titular está obligado a desarrollar en la ejecución del proyecto o actividad.

\section{Análisis del Proyecto de Ley en materia de fiscalización ambiental y AAI}

\subsection{Colaboración Privada en Funciones Públicas}

El Proyecto de Ley postula un sistema de evaluación de conformidad de las RCA, siendo la Superintendencia de Medio Ambiente, la autoridad pública que coordinará a los demás organismos del Estado con competencia ambiental y supervigilará un

\footnotetext{
CONAMA, "Sistema de Evaluación y Certificación de Conformidad de Resoluciones de Calificación Ambiental: Un Caso de Colaboración Privada en el Ejercicio de Funciones de Control Ambiental", Santiago, 2004, página 54.

39 FERNÁNDEZ, op. cit, páginas 515 y 516.
} 
sistema de certificación de normas ambientales, en el que entes privados colaboran en las funciones de control, inspección y certificación ambiental. ${ }^{40}$

La idea es "coordinar un sistema de certificación de conformidad de las normas ambientales, y que aun pudiendo significar en principio una acción o intervención sobre las materias objeto de inspección, no significa un desvalor de las competencias propias de cada administración, en la medida que estas potestades de coordinación jamás pueden servir para suplantar la distribución constitucional o legal, de las competencias respectivas" ${ }^{41}$.

Por tanto, se desprende que no se producirá un "vaciamiento", renuncia o sustitución propiamente tal de funciones públicas en favor los privados, sino más bien, sólo una delegación parcial de la función de fiscalización ambiental. Cabe destacar que la Administración no perderá la facultad de intervenir directamente en la fiscalización, aun cuando se esté desarrollando una AAI.

Es conveniente agregar además que, en caso de verificación o constatación de incumplimiento de la normativa ambiental y/o de las condiciones establecidas en la RCA, el ejercicio de la potestad sancionatoria se ejercerá única y exclusivamente por la Administración, sin "colaboración" de los privados. Es decir, en ningún caso se les otorgarán facultades de sanción a los particulares que desarrollan las AAI, sino que, éstos sólo proporcionarán los antecedentes necesarios para que la autoridad evalúe y decida si sanciona o no en caso de constatar un incumplimiento.

Como lo señala un documento elaborado por CONAMA, "en suma el objetivo final de esta iniciativa de modificación de la LBMA es lograr un reforzamiento de las funciones fiscalizadoras ambientales de los sectores, a nivel nacional y regional, fomentando la coordinación interinstitucional, y reconocer la función profesional de los consultores ambientales y demás expertos que apoyen la gestión ambiental privada, por la vía de organismos externos certificadores o verificadores de la normativa ambiental" ${ }^{42}$.

Este fenómeno responde a la adecuación de la Administración a los tiempos actuales, en los cuales "la técnica y su complejidad conducen a un progresivo proceso de traslación hacia manos privadas de verdaderas funciones de autoridad, de contenido jurídico, como es la función declarativa o de certificación del cumplimiento de la legislación vigente" ${ }^{33}$.

Sin perjuicio de lo anterior, se contempla la permanente fiscalización y supervigilancia de la Superintendencia de Medio Ambiente a las consultoras y/o certificadoras que desarrollen las AAI, pues como sostiene CANALS, son justamente las instancias públicas las garantes últimas del buen funcionamiento del sistema. ${ }^{44}$

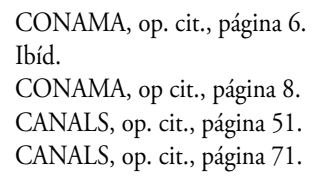




\subsection{Acreditación}

Previo a ejercer las funciones públicas de control, inspección y certificación ambiental, los privados que pretendan realizar dichas labores, deben estar debidamente acreditados por un organismo competente. En efecto, para que tengan el carácter de colaboradoras de las funciones públicas, los privados deben estar previamente certificados por una entidad acreditadora ${ }^{45}$, en base a su idoneidad técnica y solvencia económica.

$\mathrm{Al}$ respecto, DOLORS señala que la entidad de acreditación constatará que un organismo privado (auditor ambiental) cumple con las características, condiciones y requisitos técnicos, materiales y de personal, establecidos normativamente para contar con la aptitud necesaria para ejercer la función de control, inspección y certificación ambiental. Agregando que, "por lo tanto, la acreditación es una actividad reglada, de simple comprobación de requisitos". ${ }^{46}$

Entre otros requisitos, el Proyecto de Ley establece la incompatibilidad de elaborar una DIA o EIA en el marco de una consultoría ambiental y, posteriormente, como auditor, inspeccionarla. Asimismo, se establecen ciertos parámetros mínimos de idoneidad para ejercer la auditoría ambiental, en especial, experiencia calificada, personal idóneo, infraestructura y equipamiento suficiente para desarrollar las labores solicitadas.

En definitiva, se estima que con la acreditación de las personas naturales o jurídicas que desarrollen las AAI, se establecen las garantías mínimas para que el sistema de colaboración privada en la fiscalización ambiental funcione de manera imparcial, eficiente y transparente.

\subsection{Certificación Ambiental}

Uno de los aspectos centrales del Proyecto de Ley en materia de fiscalización ambiental, se refiere a la incorporación de incentivos a los particulares para el cumplimiento de la normativa ambiental. Por cierto, en caso de que el organismo privado que desarrolla la AAI, también denominado certificador, constate el cumplimiento de la normativa ambiental, otorgará al titular del proyecto o actividad sometida a control e inspección una certificación de conformidad de la RCA. ${ }^{47}$

La certificación se ha definido en la doctrina comparada, en términos generales, como el conjunto diverso de procedimientos de inspección y control realizado por la administración o agentes privados colaboradores. ${ }^{48}$

45 En este caso, probablemente el organismo acreditador sea el Instituto Nacional de Normalización (INN), según se expone en CONAMA, op. cit.

CANALS, op. cit., página 146.

47 Sin perjuicio de lo anterior, el Proyecto de Ley considera extender el ámbito de aplicación del rol de los privados a la inspección, control, verificación, medición y análisis de cumplimiento de las normas, condiciones y medidas de la RCAs, Planes de Prevención, Planes de Descontaminación, Normas de Calidad, Normas de Emisión y Planes de Manejo.

48 CONAMA, op cit., página 33. 
En virtud de ella, el Estado reconoce la competencia técnica, independencia e idoneidad moral de una entidad privada para que ella dé fe del cumplimiento de ciertas condiciones de una actividad o proyecto. ${ }^{49}$

Normalmente, bajo estos esquemas, la certificación puede operar mejorando la posición jurídica del titular del proyecto o actividad, frente a los procedimientos administrativos de autorización como a la fiscalización ambiental, en el entendido de que podrá exhibir su certificado como prueba de cumplimiento de todo o parte de la normativa ambiental que le sea aplicable ${ }^{50}$, así como de las condiciones o exigencias ambientales impuestas por la RCA.

Sin perjuicio de lo anterior, el titular del proyecto o actividad sometido a AAI puede obtener beneficios comerciales, debido al mejoramiento de su posición de mercado, de cara a potenciales compradores de sus productos. En tal sentido, la certificación ambiental se transforma en un instrumento que subsana la asimetría de información entre productores y consumidores, permitiendo decisiones de consumo informadas. ${ }^{51}$

\section{Temas pendientes para una posterior regulación reglamentaria}

Resulta lógico entender que un proyecto de ley, no pretenda regular exhaustivamente todas y cada una de las materias que trata, dejando para futuras regulaciones a nivel reglamentario, la tarea de completar las materias reguladas por ley.

En relación a la acreditación, saltan a la vista ciertos puntos que deberán ser resueltos vía reglamento, como por ejemplo: ¿̨a acreditación será temporal o permanente?, ¿deberá renovarse?, ¿la determinación de la "suficiencia" de la infraestructura y equipamiento para realizar las AAI será un parámetro único, o más bien, atenderá a la envergadura del proyecto o actividad a ser auditado? En otras palabras, se plantea la interrogante de si existirán distintas categorías de auditores, como asimismo diferentes categorías de proyectos o actividades. En caso de que se rechace la acreditación: ¡se podrá impugnar dicha decisión?, ¿bastará con presentar nuevamente los antecedentes, subsanado las deficiencias?, etc.

Respecto de la certificación ambiental, surgen más y mayores interrogantes, especialmente en relación al valor jurídico del certificado otorgado. Sobre el particular, el Proyecto de Ley no aporta mayores luces, ya que, se remite a señalar que las características del certificado y vigencia, serán determinadas por la Superintendencia, de acuerdo a la naturaleza de las mismas y conforme las normas que establezca el Reglamento. En este sentido, surgen dudas en torno a cual es la naturaleza jurídica y el valor proba-

49 BERMÚDEZ, J. (2006), op. cit., página 287. Al respecto, Bermúdez señala que se da fe respecto del cumplimiento de ciertas condiciones ambientales de un producto, proceso o establecimiento. Se estima que en el caso de las AAI lo que se audita es el proyecto actividad en su conjunto, al contrario de lo que podría suceder en otro tipo de certificaciones, como por ejemplo en materia eléctrica.

50 BERMÚDEZ, J. (2006), op. cit., página 288.

51 Ibíd. 
torio de la certificación: ¡será pública, privada o pública-privada?, ¿tendrá la misma validez jurídica que los certificados otorgados por la Administración?, ¿constituirá una presunción de cumplimiento de la normativa ambiental?, ¿será sólo una opinión calificada?, ¿aadmitirá prueba en contrario?, etc.

En cuanto a los procedimientos y metodologías de las AAI, ¿existirá un procedimiento reglado para las AAI?, ¿se determinará caso a caso por la autoridad, en atención al proyecto o actividad en particular?, ¿se incluirán principios generales que puedan subsanar vacíos o discordancias normativas? Ahora, respecto del rol de las AAI, se deberá entender que ¿sólo deberá existir constatación de hechos?, ¿será preciso emitir una opinión?, ¿ ¿se deberán incluir sugerencias o medidas correctoras, cuando se estime pertinente? En este punto, resulta crucial delimitar claramente la labor de los auditores, en especial para que éstos no excedan sus atribuciones. Asimismo, es de especial importancia determinar cual deberá ser el contenido mínimo de los informes y si éstos serán o no vinculantes para la Administración.

Respecto de la amplitud de su implementación, seguramente el sector privado se preguntará si las AAI se considerarán obligatorias para todos los proyectos y actividades sometidos al SEIA o sólo para aquellos de gran envergadura y complejidad, tal como sucede hoy en día. En esta misma línea, resulta crucial determinar si existirá distinción entre DIAs y EIAs, ¿acaso procederán las AAI siempre? Se advierte que, en ciertos casos, puede no justificarse una AAI, por ejemplo, en caso de que se trate de una DIA que consiste en una modificación menor de un proyecto recientemente auditado. En este tipo de casos, ¿existirá la posibilidad de que la Administración decida no exigir la AAI, por no considerarse necesario y estimarse un costo excesivo?, ¿`será posible solicitar la exención de ser auditado, en atención a causas justificadas?, etc.

Por otra parte, surge la duda acerca de la posibilidad de establecer modalidades de certificación, por ejemplo, puras y simples (favorable o desfavorable), parciales o totales, o incluso condicionadas, en virtud de las cuales se permita que el auditado pueda corregir o modificar su proyecto o actividad en orden a acceder a una certificación favorable posterior.

En caso de una certificación desfavorable, cabe preguntarse entre otras: ¿se constatará o presumirá el incumplimiento de la RCA?, ¿conllevará necesariamente una sanción por incumplimiento o sólo servirá de antecedente para un eventual proceso sancionatorio?, ¿se podrá impugnar una certificación desfavorable?, ¿qué sucederá si la información contenida en los informes de las AAI no se condice con los hechos o los ensayos, monitoreos y/o análisis realizados no se ajustaron a las metodologías exigidas?

En materia de responsabilidad, probablemente se cuestione la necesidad de exigir a los auditores ambientales una póliza de seguro que cubra las responsabilidades que pudieran derivarse de su actuación ${ }^{52}$. $\mathrm{Al}$ respecto, no resulta tan evidente que la

52 Imagínese, por ejemplo, que una determinada actividad o proyecto autorizado por una RCA causa daños a terceros -o al medio ambiente-, pese a haber sido controlada periódicamente por un auditor acreditado. En este caso, lo 
responsabilidad de los privados exime de responsabilidad al Estado, puesto que, éste ejerce el rol de garante (supervigilante) del sistema y, por ende, podría atribuírsele culpa in vigilando.

\section{Conclusiones}

El Proyecto de Ley que Rediseña la Institucionalidad Ambiental, sin duda, constituirá un gran avance en materia de fiscalización ambiental, independientemente de que queden ciertos aspectos puntuales pendientes para una regulación reglamentaria posterior.

En primer término, se podrá sincerar la labor de las AAI, ya que, se sustentará legalmente el actuar de los privados en la función pública de la fiscalización ambiental, dejando atrás ambigüedades conceptuales e irregularidades administrativas. Se puede sostener que la naturaleza jurídica de las AAI se alterará, puesto que, al contar con una norma legal de respaldo, éstas dejarán de responder al cumplimiento de una de las condiciones o exigencias ambientales de la RCA, para convertirse derechamente en un caso de colaboración privada en la función pública de fiscalización.

Como bien señala FERNANDEZ, este modelo presenta innegables ventajas, puesto que hará recaer sobre los titulares de los proyectos o actividades objeto de control la obligación de demostrar periódicamente que cumplen con las normativa y, en particular, con especificaciones de carácter marcadamente técnico. Además, es previsible suponer que el grado de efectivo cumplimiento de la legalidad sea superior que un sistema tradicional sujeto a inspección administrativa aleatoria. ${ }^{53}$

Asimismo, este modelo permitirá descongestionar a la Administración de tareas eminentemente técnicas, posibilitando que se concentre en las actuaciones técnicojurídicas, no generándose costos para el Estado y, junto con lo anterior, indirectamente se generarán ingresos y empleos para el sector privado. ${ }^{54}$ Ello, sin duda, hará más eficiente la actividad de la Administración del Estado, al permitirle reorientar el uso de recursos humanos y materiales y, en definitiva, alcanzar mejor el cumplimiento de la función de protección ambiental. ${ }^{55}$

Es importante destacar que la consagración legal además otorgará una serie de garantías para que el sistema de colaboración privada en materia de fiscalización ambiental funcione de manera imparcial, eficiente y transparente.

más probable es que el titular del proyecto o actividad alegue en su defensa que está debidamente autorizado por la respectiva RCA y, no sólo ha dado cumplimiento a ella, sino que además se ha certificado su cumplimiento por una AAI. Hipótesis extraída de: CONAMA, op. cit., página 45.

53 FERNANDEZ, op. cit., páginas 523 y 524.

54 Ibíd.

55 BERMÚDEZ, J. (2006), op. cit., página 291. 
Por otra parte, quienes se dedican a las auditorías ambientales, ya deben estar sacando cuentas alegres, considerando que se ampliará considerablemente el ámbito en el cual los privados pueden colaborar, extendiéndose a la fiscalización del cumplimiento de Planes de Prevención y/o Descontaminación, Normas de Calidad, Normas de Emisión y Planes de Manejo.

A su vez, se generarán incentivos para el cumplimiento de la normativa ambiental, lo cual es de la mayor relevancia, ya que, se cambia el enfoque de inspector-sancionador, por uno en el cual los privados muestren interés en ser fiscalizados para así demostrar su "sustentabilidad" y, por ende, su Responsabilidad Social Empresarial.

En fin, la instauración de un modelo de certificación ambiental implicará un "cambio cultural" en la gestión ambiental, pues se transitará desde uno de intervención unilateral de la administración a uno de base colaborativa, en que los privados participen como entidades colaboradoras en las funciones de control, inspección y certificación. ${ }^{56}$ 